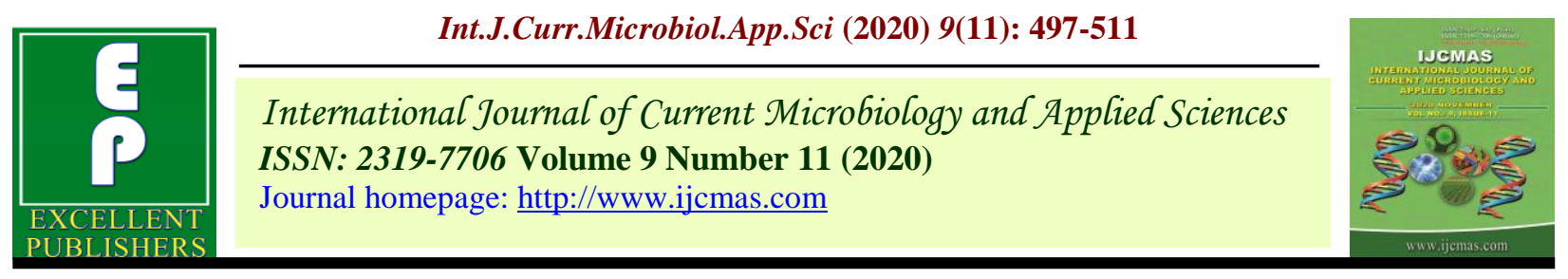

Review Article

https://doi.org/10.20546/ijcmas.2020.911.061

\title{
Probiotics, Prebiotics, Synbiotics and its Health Benefits
}

\section{T. Thilagavathi*}

Department of Food Science and Nutrition, Agricultural College and Research Institute, Tamil Nadu Agricultural University, Vazhavachanur, Thiruvannamalai, Tamil Nadu, India

*Corresponding author

\section{A B S T R A C T}

\begin{tabular}{|l|}
\hline Ke y w o r d s \\
Probiotics, \\
Prebiotics, \\
Synbiotics, Foods, \\
Health benefits
\end{tabular}

Functional foods have become a part of an everyday diet and are demonstrated to offer potential health benefits beyond the widely accepted nutritional effects. Currently, the most important and frequently used functional food compounds are probiotics and prebiotics, or they are collectively known as 'synbiotics'. Most commonly used probiotic strains are: Bifidobacterium, Lactobacilli, S. boulardii, B. coagulans. Prebiotics like Fructooligosacchaides (FOS), galacto-oligosaccharides (GOS), xyloseoligosaccharide (XOS), Inulin; fructans are the most commonly used fibers which when used together with probiotics are termed synbiotics and are able to improve the viability of the probiotics.

\section{Introduction}

Probiotics are defined as 'live microorganisms which when administered in adequate amount confer health benefits to the host' (FAO/WHO, 2002). Alternatively, probiotics have been defined as live microbial feed supplements that beneficially affect the host animal by improving its intestinal microbial balance (Fuller, 1989). Probiotics were originally used to improve the health of both animals and humans through the modulation of the intestinal microbiota. At present, several well-characterized strains of Lactobacilli and Bifidobacteria are available for human use to reduce the risk of gastrointestinal (GI) infections or treat such infections (Salminen et al., 2005). Some of the beneficial effects of probiotic consumption include improvement of intestinal health by the regulation of microbiota, and stimulation and development of the immune system, synthesizing and enhancing the bioavailability of nutrients, reducing symptoms of lactose intolerance, and reducing the risk of certain other diseases (Fig. 1-3) (Kumar et al., 2009a, Kumar et al., 2009b, Kumar et al., 2010, Kumar et al., 2011a, Kumar et al., 2011b; Nagpal et al., 2007, Nagpal et al., 2010, Nagpal et al., 2011; Yadav et al., 2007a, Yadav et al., 2007b, Yadav et al., 2008). The primary clinical 
interest in the application of probiotics has been in the prevention of and treatment for GI infections and diseases (Parvez et al., 2006). Gut microbiota deviations have been associated with enhanced risk of specific diseases; therefore, modulation of an unbalanced indigenous microbiota forms the rationale of probiotic therapy (Turnbaugh et al., 2006).

Also, the development of adjuvant or alternative therapies based on bacterial replacement is becoming important owing to the rapid emergence of antibiotic-resistant pathogenic strains and the adverse consequences of antibiotic therapies on the protective flora, which enhances the risk of infection (Forestier et al., 2001).

However, the use of probiotics should be further investigated for their benefits and possible side effects, if any. As the knowledge about intestinal microbiota, nutrition, immunity, and genetics in health and disease has increased in the past years, such information could certainly help to develop new probiotic strains with disease-specific functions and could also facilitate the understanding of when to use probiotics and how they affect specific pathological states. However, it is important that the probiotic strains for human use should undergo animal studies followed by human clinical trials in order to authenticate the suitability, safety, and benefits of probiotics for human consumption and development of functional foods.

\section{Functional foods}

Functional foods are fortified or enriched during processing and then marketed as providing some benefit to consumers. Sometimes, additional complementary nutrients are added, such as Vitamin D to milk. Functional foods are "Ordinary food that has components or ingredients added to give it a specific medical or physiological benefit, other than a purely nutritional effect". All functional foods must meet three established requirements: Foods should be

Present in their naturally occurring form, rather than a capsule, tablet, or powder

Consumed in the diet as often as daily

Should regulate a biological process in hopes of preventing or controlling disease.

\section{Functional foods as immune function}

Immune function throughout life can be influenced by nutrition. Possible ingredients for the development of functional foods that could contribute to optimal immune response include the antioxidant vitamins, trace elements (e.g. zinc, copper and manganese), n-3 and n-6 PUFAs, 1-arginine, nucleotides and nucleosides, probiotics, prebiotics and synbiotics.

\section{Functional foods as gastrointestinal health}

The GI tract is an obvious target for the development of functional foods because it acts as an interface between the diet and all other metabolic functions.

GI function depends on an appropriate balance of healthy bacteria to prevent the invasion of harmful bacteria. One of the most promising areas for the development of functional foods lies in the use of ingredients to modify the composition and metabolic activity of the gut microflora:

Probiotics;

Prebiotics;

Synbiotics (mixtures of probiotics and prebiotics). 


\section{Classification of functional foods}

Functional foods are classified in to

Probiotic

Prebiotic

Synbiotic

\section{Probiotic}

Probiotic is a greek word which means "for life" and it is generally used to name the bacteria associated with the beneficial effects for the humans and animals. Live microorganisms that, when administered in adequate amounts, confer a health benefit on the host. Probiotics are living microorganisms which upon ingestion in sufficient numbers exert health benefits beyond basic nutrition. Probiotics are a viable microbial dietary supplement which uplifts the health of the host.

Probiotics are living microorganisms which include Lactobacillus species, Bifidobacterium species and yeasts. When ingested in certain amounts these have a positive impact on human health, by improvement of the balance of the intestinal microflora (MacFarlane and Cummings, 1999; Morelli et al., 2003; Schrezenmeir and de Vrese, 2001). In fact, one of the oldest methods used to produce and preserve food was fermentation carried out by microorganisms, and cultured dairy products and soured milks were often used therapeutically. Recent controlled scientific investigation supports these traditional views, suggesting that probiotics are a valuable part of a healthy diet.

In the stomach, food is mixed with gastric juices, containing digestive enzymes and hydrochloric acid, producing the chyme. This goes to the small intestine, where more enzymes and bile are joined, to complete the breakdown of dietary proteins, fats and sugars. Most nutrients are absorbed in the small intestine and the rest passes into the large intestine, or colon, where water and electrolytes are absorbed and fecal matter is expelled through the rectum. The gastrointestinal tract is a complex ecosystem, with a delicate balance between the intestinal microflora and the host. In the large intestine, microbes complete the digestion of any food components that were not digested in the small intestine, such as lactose in lactose intolerant people or some fibers resistant to the enzymes in the small intestine.

The intestinal microflora is important for the maturation of the immune system, the development of normal intestinal morphology and the maintenance of a balanced inflammatory response. On the other hand, the microflora reinforces the barrier function of the intestinal mucosa, thus preventing the attachment of pathogenic microorganisms and the entry of allergens. Moreover, some microorganisms may positively contribute to the body's requirements for certain vitamins.

The different probiotics include: Bifidobacterium, Lactobacillus (or lactic acid bacteria - LAB), Lactococcus, Saccharomyces, Streptococcus thermiphilus and Enterococcus. Most of the presently available probiotics are bacteria, however, Saccharomyces boulardii is an example of a probiotic yeast.

Regarding the effects of probiotics on human health, it is important to recognize that different strains, species and genera of bacteria may have different effects, and therefore, the health benefits claimed for a certain probiotic may be dependent on the specific conditions tested. However, many studies claim that certain strains consumed at adequate levels positively influence human health, namely concerning diarrhea (van Niel 
et al., 2002; Weizman et al., 2005), antibiotics (Cremonini et al., 2002; Johnston et al., 2006), irritable bowel syndrome (Kajander et al., 2005; Quigley and Flourie, 2007), inflammatory bowel disease (Ghosh et al., 2004; Penner and Fedorak, 2005), lactose intolerance (de Vrese et al., 2001; Pelletier et al., 2001), hypertension (Parvez et al., 2006; Sydorchuk et al., 2005), hepatic encephalopathy (de Santis et al., 2000; Solga, 2003), cancer (Brown and Valiere, 2004; Donaldson, 2004; Parvez et al., 2006), immune system (Brown and Valiere, 2004; Galdeano and Perdigón, 2006), vaginal infections (Brown and Valiere, 2004; Reid et al., 2004), Helicobacter pylori (Nam et al., 2002; Sgouras et al., 2004), kidney stones (Azcarate-Peril et al., 2006; Federici et al., 2004), cholesterol (Liong and Shah, 2005; Pereira et al., 2003), allergies and eczema (Isolauri et al., 2000; Pohjavuori et al., 2004).

\section{Probiotic foods for improved gastrointestinal health}

Probiotics are the well-known means to target the GI microbes with proven disease preventing/curing attributes. Viable probiotic bacteria such as Lactobacilli and Bifidobacteria can survive in sufficient numbers to assist the GI tract to become metabolically active. Their therapeutic effects have been confirmed in clinical trials and they have been utilized effectively in formulation of certain functional and nutritional foods. Probiotics primarily targets immune system through exerting anti-microbial activity, enhancing the proliferation of immunedefense cells, regulating certain metabolic enzymes and inhibiting the degenerative processes. The exact mechanisms related to beneficial effects of probiotics vary with target group and microorganisms. The food products which assist in improving the GI health are also termed as "colonic foods" and include probiotics, prebiotics and synbiotics.

\section{Advantages of probiotic foods}

Produce lactic acid- lowers the $\mathrm{pH}$ of intestines and inhibiting bacterial villains such as Clostridium, Salmonella, Shigella, E. coli, etc.

Decreases the production of a variety of toxic or carcinogenic metabolites.

Aid absorption of minerals, especially calcium, due to increased intestinal acidity.

Production of $\beta$-D galactosidase enzymes that break down lactose.

Produce a wide range of antimicrobial substances acidophilin and bacitracin etc. help to control pathogenic bacteria.

Produce vitamins (especially Vitamin B and vitamin $\mathrm{k}$

Act as barriers to prevent harmful bacteria from colonizing the intestines Cont.

\section{Potential health benefits of probiotics include}

Reduced incidence or severity of GI infections;

Alleviation of lactose intolerance;

Overall improvement in gut function, including reduction in constipation as well as diarrhoea.

Probiotics display numerous health benefits beyond providing basic nutritional value. Probiotics have been used in fermented food products for centuries. However, nowadays it has been claimed that probiotics can serve a dual function by their potentially importing health benefits. The health benefit of fermented foods may be further enhanced by supplementation of Lactobacillus and Bifidobacterium species (Shah, 2000). L. acidophilus, Bifidobacterium spp. and $L$. casei species are the most used probiotic cultures with established human health in dairy products, whereas the yeast Saccharomyces cerevisiae and some E. coli 
and Bacillus species are also used as probiotics.

There is increasing evidence in favour of the claims of beneficial effects attributed to probiotics, including improvement of intestinal health, enhancement of the immune response, reduction of serum cholesterol, and cancer prevention. Several studies have documented probiotic effects on a variety of gastrointestinal and extra intestinal disorders, including prevention and alleviation symptoms of traveler's diarrhea and antibiotic associated diarrhea, inflammatory bowel disease (Marteau et al., 2002), lactose intolerance (de Vrese et al., 2001), protection against intestinal infections (Reid et al., 2001), and irritable bowel syndrome. Some probiotics have also been investigated in relation to reducing prevalence of atopic eczema later in life (Gueimonde et al., 2006), vaginal infections, and immune enhancement (Isolauri et al., 2001), contributing to the inactivation of pathogens in the gut, rheumatoid arthritis, improving the immune response of in healthy elderly people (Ibrahim et al., 2010), and liver cirrhosis.

In addition, probiotics are intended to assist the body's naturally occurring gut microbiota. Some probiotic preparations have been used to prevent diarrhea caused by antibiotics, or as part of the treatment for antibiotic-related dysbiosis. Although there is some clinical evidence for the role of probiotics in lowering cholesterol but the results are conflicting.

Probiotics have a promising inhibitory effect on oral pathogens especially in childhood but this may not necessarily lead to improved oral health (Twetman and Stecksen-Blicks, 2008). Antigenotoxicity, antimutagenicity and anticarcinogenicity are important potential functional properties of probiotics, which have been reported recently. Observational data suggest that consumption of fermented dairy products is associated with a lower prevalence of colon cancer, which is suggested that probiotics are capable of decreasing the risk of cancer by inhibition of carcinogens and pro-carcinogens, inhibition of bacteria capable of converting procarcinogens to carcinogens (Vasiljevic and Shah, 2008).

\section{Allergy prevention and recovery}

Experimental evidence indicates that probiotics are effective in treating atopic eczema in infants. It has also been shown that the incidence of allergies in infants with a high risk of allergy can be halved with the consumption of certain probiotics by their mothers when pregnant and by the infant after birth. It is thought that consumption of probiotics helps to form a normally functioning immune system, preventing allergies (Ouwehand, 2007).

\section{Treatment of peptic ulcers}

Helicobacter pylori are a pathogenic bacterium that causes peptic ulcers and other gastric problems. Helicobacter pylori are normally treated with antibiotics. This treatment is expensive and has negative side effects. The consumption of probiotics with antibiotics is thought to be the most effective and safest treatment (Lesbros-Pantoflickova et al., 2007).

\section{Diarrhea}

Evidence indicates that probiotic bacteria in foods can help prevent and treat diarrhea in children. Rotavirus infections are a common cause of diarrhea in children. In clinical trials, infected children who consumed probiotic fermented milk had lower rates of diarrhea. Probiotic treatments have also been used to effectively treat antibiotic associated diarrhea (Agrawal, 2005) 


\section{Blood pressure regulation}

Milk is fermented by bacteria and the protein in the milk is hydrolyzed into smaller peptides. The peptides are absorbed in the small intestine. Consumption of these peptides in milk and yogurt has been shown in clinical studies to lower blood pressure in some individuals (Jauhiainen and Korpela, 2007).

\section{Regularity}

The consumption of probiotics reduces the transit time for the movement of wastes through the intestines. This results in reduced constipation and may help prevent colon cancer. Prebiotics also decrease transit time through the intestines because they are a form of fiber (Dempsters, 2007).

\section{Reduction of infection}

Probiotics and prebiotics have been shown to reduce infections in sick and postoperative patients. Because the use of antibiotics reduces the population of intestinal bacteria, using probiotics and prebiotics to repopulate the digestive tract, ensures the presence of a healthy $n$ of good bacteria to prevent infection (Agrawal, 2005).

\section{Lactose digestion}

Individuals with lactose intolerance are missing important digestive enzyme, lactase. Probiotic bacteria make the lactase enzyme and consumption of these bacteria can help lactose digestion (Stanton et al., 2001).

\section{Immune function}

Consumption of probiotics can enhance natural immune functions (Agrawal, 2005).

\section{Cancer prevention}

Probiotics have been shown, in vitro and in animal studies, to prevent cancer by reducing
DNA damage by carcinogens (Stanton et al., 2001).

\section{Lowering cholesterol}

A range of $\mathrm{LAB}$ able to break down bile in the gut, thus inhibiting its reabsorption (which enters the blood as cholesterol).

\section{Prebiotics}

A prebiotic is a non-digestible component which beneficially affects the host by selectively stimulating the growth and/or activity of one or a limited number of colonic bacteria, thereby improving the health of the host. The term prebiotic is applied to non digestible food ingredients that may have a positive impact by the improvement of the intestinal flora. Prebiotics are mostly oligosaccharides, which stimulate selectively the growth of bifidobacteria, being therefore referred to as bifidogenic factors. These include: fructooligosaccharides, inulins, isomalto-oligosaccharides, lactilol, lactosucrose, lactulose, pyrodextrins, soy oligosaccharides, transgalactooligosaccharides and xylo-oligosaccharides. The positive effects of prebiotics include antimicrobial, anticarcinogenic, hypolipidemic, glucosemodulatory and antiosteoporotic activities. They may be used for the treatment of constipation, hepatic encephalopathy and inflammatory bowel disease. They can protect against some intestinal pathogens and may exert favorable lipid effects as well as have some benefit in diabetes mellitus. Besides, prebiotics also have a very important role in improving mineral absorption and balance, for instance, they may enhance the colonic absorption of some minerals.

Prebiotics, non-digestible food components that can stimulate growth and/or modify the metabolic activity of specific bacterial species already present in the gut, might also improve 
gut health. They are also being evaluated for beneficial effects on the immune system and the potential to reduce risk of colon cancer. Their ability to increase production of short chain fatty acids in the colon is associated with increased absorption of minerals such as calcium and magnesium. Examples: inulin, garlic, onions, chicory root, Asparagus, whole wheat, rye, barley.

Commonly known prebiotics are:

Oligofructose

Inulin

Galacto-oligosaccharides

Lactulose

Breast milk oligosaccharides

Lactulose is a synthetic disaccharide used as a drug for the treatment of constipation and hepatic encephalopathy. The prebiotic oligofructose is found naturally in many foods, such as wheat, onions, bananas, honey, garlic, and leeks. Oligofructose can also be isolated from chicory root or synthesized enzymatically from sucrose. Fermentation of oligofructose in the colon results in a large number of physiologic effects, including:

Increasing the numbers of bifidobacteria in the colon

Increasing calcium absorption

Increasing fecal weight

Shortening gastrointestinal transit time

Possibly, lowering blood lipid levels

The increase in colonic bifidobacteria has been assumed to benefit human health by producing compounds to inhibit potential pathogens, by reducing blood ammonia levels, and by producing vitamins and digestive enzymes.

\section{Functions of prebiotics}

Prebiotics reach the colon without being digested because of their chemical nature. A part of the material is not digested by pancreatic and small-bowel enzymes in the human gut and therefore, reaches the large bowel. The whole length of human gut is occupied by microorganisms with population numbers and species distribution characteristics of specific region of guts (Macfarlane and Macfarlane, 1997). In the gut the relatively more stable colonies are in large intestines than smaller intestines because the transit time in small intestines is faster (4-6 h) than large intestines $(48-70 \mathrm{~h})$ in adults (Macfarlane and Gibson, 1994). The $\mathrm{pH}$ and relatively low absorptive state of colon further supports large microbial colonisation and growth (O'Sullivan, 1996). Due to this microflora, the colon has the ability to undertake complex hydrolytic digestive functions (Cummings and Macfarlane, 1991). This involves breakdown of dietary components, complex carbohydrates and some proteins that are not hydrolysed or absorbed in the upper digestion tract. The colonic microflora derives their food from the undigested food e.g., nondigestible oligosaccharides, dietary fibre, and undigested protein. They also get their substrates from the mucin: the main glycoprotein constituent of the mucus. Therefore, any undigested food that reaches the colon e.g., nondigested carbohydrates, some peptides and proteins, certain lipids is a source of prebiotics (Mussatto and Mancilha, 2007). Prebiotics have been suggested of having various health benefits on humans. It acts as a substrate for the useful gut microorganisms.

\section{Synbiotics}

The term synbiotic is used for products that contain both probiotics and prebiotics, and which take advantage of the addition of beneficial bacteria as well as the encouragement of beneficial bacterial growth. The best synbiotic combinations currently available include bifidobacteria and fructo- 
oligosaccharides (FOS), Lactobacillus GG and inulins, and bifidobacteria and lactobacilli with FOS or inulins.

When Gibson introduced the concept of prebiotics he speculated as to the additional benefits if prebiotics were combined with probiotics to form what he termed as Synbiotics (DeVrese and Schrezenmeir, 2008). A synbiotic product beneficially affects the host in improving the survival and implantation of live microbial dietary supplements in the gastrointestinal tract by selectively stimulating the growth and/or activating the metabolism of one or a limited number of healthpromoting bacteria. Because the word "synbiotics" alludes to synergism, this term should be reserved for products in which the prebiotic compound(s) selectively favor the probiotic organism(s) (Cencic and Chingwaru 2010). Synbiotics were developed to overcome possible survival difficulties for probiotics. It appears that the rationale to use synbiotics, is based on observations showing the improvement of survival of the probiotic bacteria during the passage through the upper intestinal tract. A more efficient implantation in the colon as well as a stimulating effect of the growth of probiotics and ubiquitous bacteria contribute to maintain the intestinal homeostasis and a healthy body (Peña 2007). Several factors like $\mathrm{pH}, \mathrm{H} 2 \mathrm{O} 2$, organic acids, oxygen, moisture stress etc. have been claimed to affect the viability of probiotics especially in dairy products like yogurts (Romeo et al., 2010) (Table 1 and 2).

Table.1 Probiotic microorganisms

\begin{tabular}{|c|c|c|}
\hline Lactobacillus species & Bifidobacterium species & Others \\
\hline L. acidophilus & B. adolescentis & Bacillus cereus \\
\hline L. amylovorus & B. animalis & Clostridium botyricum \\
\hline L. brevis & B. breve & Enterococcus faecalis $^{a}$ \\
\hline L. casei & B. bifidum & Enterococcus faecium $^{a}$ \\
\hline L. rhamnosus & B. infantis & Escherichia coli \\
\hline L. crispatus & B. lactis & Lactococcus lactis subsp. cremoriss \\
\hline $\begin{array}{l}\text { L. delbrueckii subsp. } \\
\text { Bulgaricus }\end{array}$ & B. longum & Lactococcus lactis subsp. Lactis \\
\hline L. fermentum & & $\begin{array}{l}\text { Leuconostoc mesenteroides subsp. } \\
\text { Dextranicum }\end{array}$ \\
\hline L. gasseri & & Pediococcus acidilactici \\
\hline L. helveticus & & Propionibacterium freudenreichiii ${ }^{a}$ \\
\hline L. johnsonii & & Saccharomyces boulardii \\
\hline L. lactis & & $\begin{array}{l}\text { Streptococcus salivarius subsp. } \\
\text { Thermophiles }\end{array}$ \\
\hline L.paracasei & & Sporolactobacillus inulinus $^{a}$ \\
\hline \multicolumn{3}{|l|}{ L. plantarum } \\
\hline \multicolumn{3}{|l|}{ L. reuteri } \\
\hline L. salivarius & & \\
\hline L. gallinarum ${ }^{a}$ & & \\
\hline
\end{tabular}

a mainly applied in animals 
Table.2 Probiotic foods

\begin{tabular}{|c|c|c|}
\hline Probiotic foods & Prebiotic foods & Vegan sources \\
\hline $\begin{array}{l}\text { Yogurt (plain, no added sugar, active } \\
\text { cultures) } \\
\text { buttermilk } \\
\text { acidophilus milk } \\
\text { Kefir } \\
\text { Tempeh } \\
\text { Kimchi } \\
\text { Sauerkraut } \\
\text { Kombucha } \\
\text { Pickles } \\
\text { Miso } \\
\text { Dark chocolate } \\
\text { Sourdough bread } \\
\text { cheese (aged) } \\
\text { cottage cheese } \\
\text { fermented meats } \\
\text { fermented vegetables } \\
\text { fermented grains } \\
\text { kombucha } \\
\text { kvass } \\
\text { lassi } \\
\text { natto } \\
\text { raw vinegars } \\
\text { sour cream }\end{array}$ & $\begin{array}{l}\text { Garlic } \\
\text { Onions } \\
\text { Leeks } \\
\text { Asparagus } \\
\text { Bananas } \\
\text { Barley } \\
\text { Oats } \\
\text { Apples } \\
\text { Flaxseeds } \\
\text { Wheat Bran } \\
\text { Artichokes } \\
\text { Berries } \\
\text { Black beans } \\
\text { Cherries } \\
\text { Dandelion greens } \\
\text { Chicory root } \\
\text { Chickpeas } \\
\text { Eggplant } \\
\text { Endive } \\
\text { Honey } \\
\text { Legumes } \\
\text { Lentils } \\
\text { Mangoes } \\
\text { Oatmeal } \\
\text { Peas } \\
\text { Pears } \\
\text { Quinoa } \\
\text { Tomatoes } \\
\text { White beans } \\
\text { Whole grains }\end{array}$ & $\begin{array}{l}\text { Coconut water } \\
\text { kefir } \\
\text { Live cultured nondairy yogurt (coconut, soy) } \\
\text { Pickled or fermented fruits and vegetables } \\
\text { Kombucha tea } \\
\text { Tempeh }\end{array}$ \\
\hline
\end{tabular}

Fig.1 Functions of probiotics

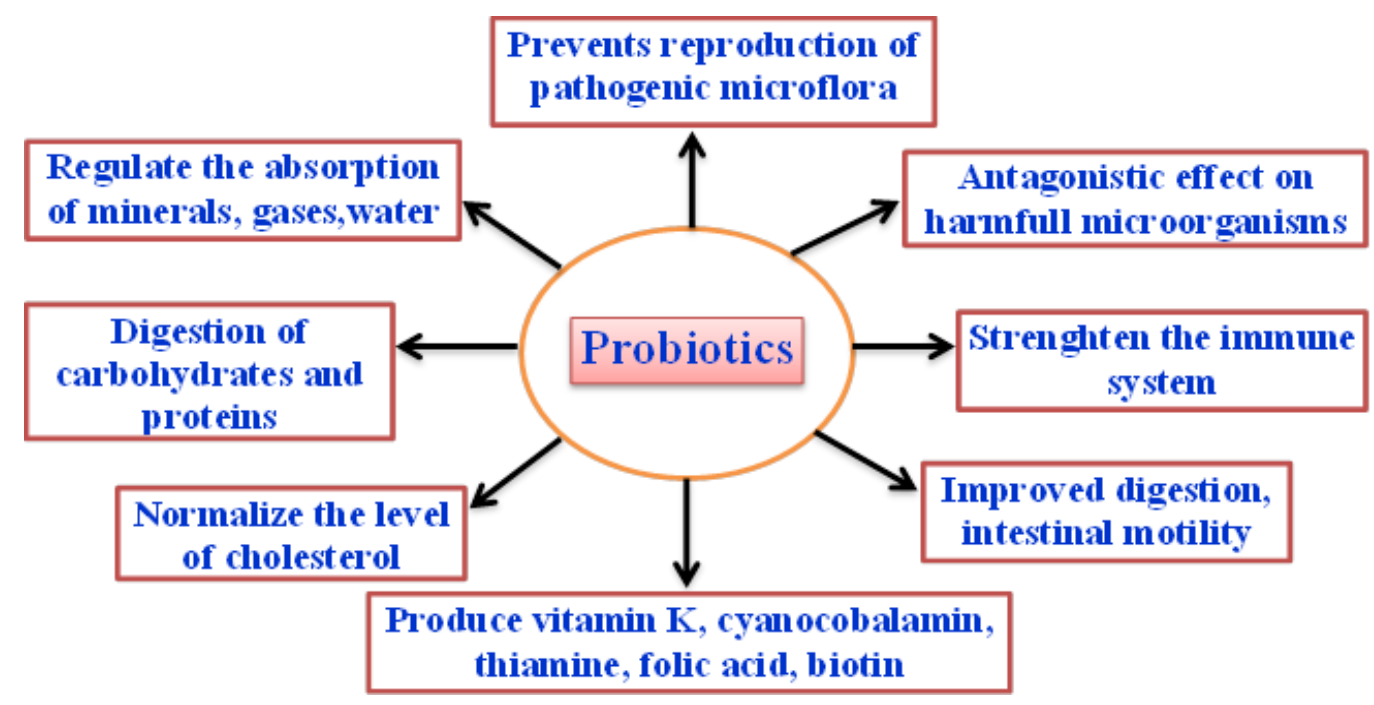


Fig.2 Health attributes of probiotics

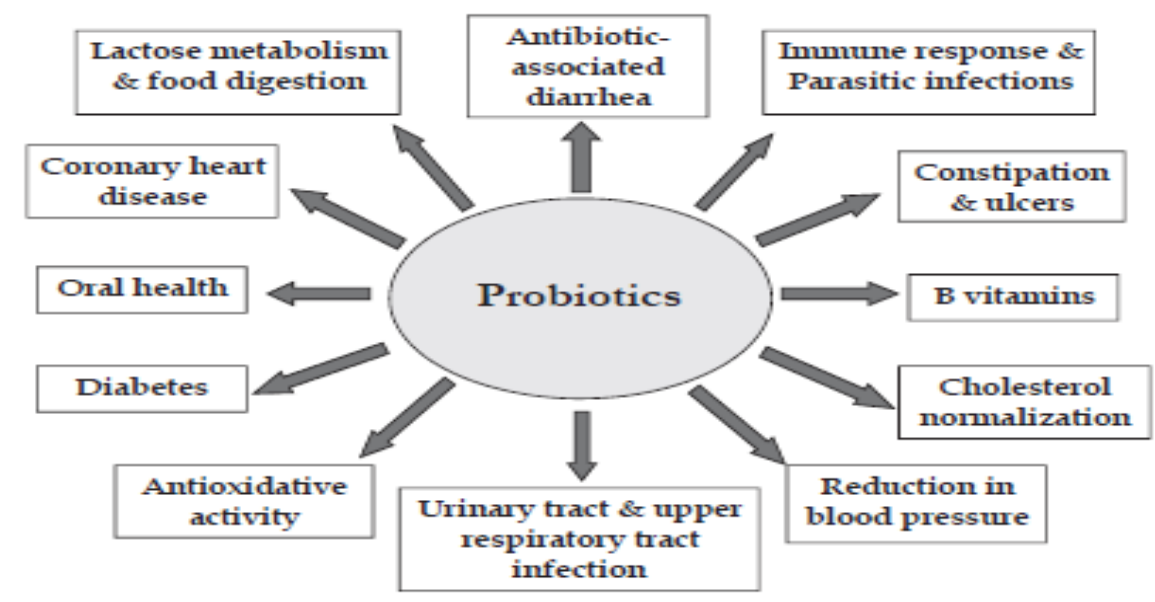

Fig.3 Health benefits of probiotics

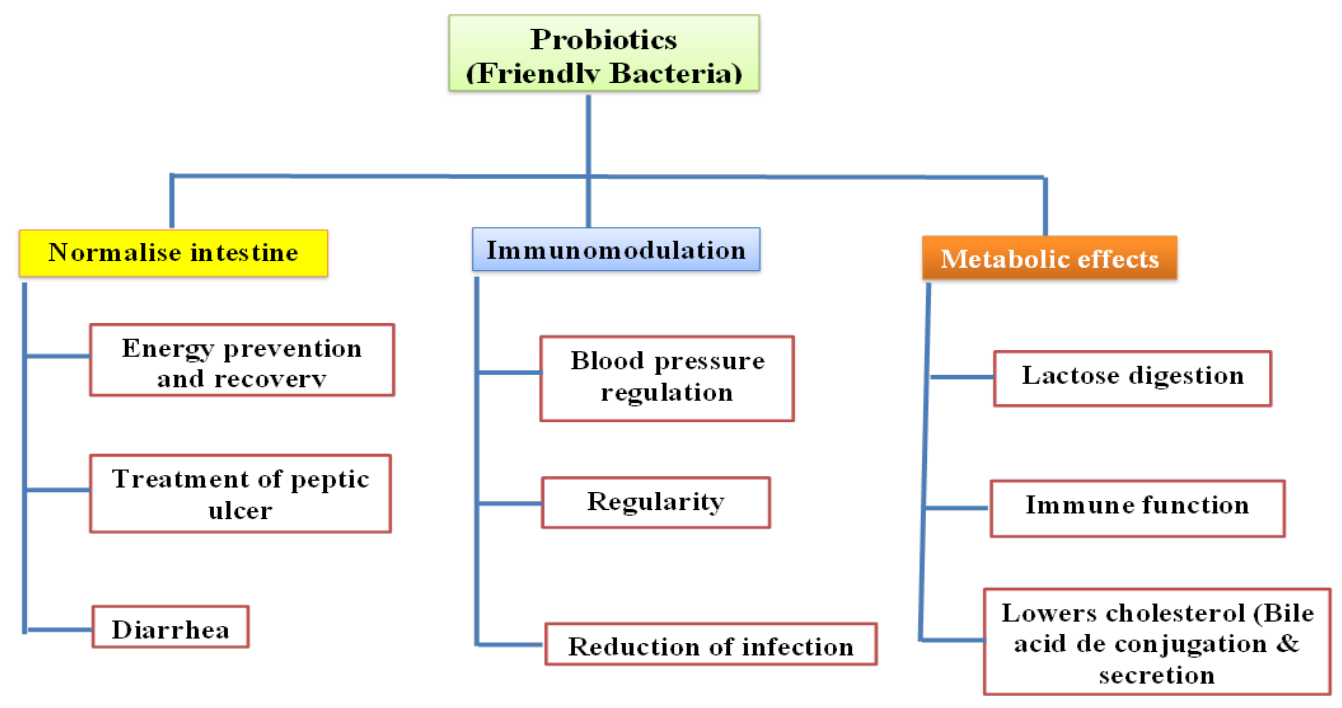

The probiotic strains used in synbiotic formulations include Lacbobacilli, Bifidobacteria spp, S. boulardii, B. coagulans etc., while the major prebiotics used comprise of oligosaccharides like fructooligosaccharide (FOS), GOS and xyloseoligosaccharide (XOS), inulin, prebiotics from natural sources like chicory and yacon roots, etc. The health benefits claimed by synbiotics consumption by humans include: 1) Increased levels of lactobacilli and bifidobacteria and balanced gut microbiota, 2) Improvement of liver function in cirrhotic patients, 3) Improvement of immunomodulating ability, 4) Prevention of bacterial translocation and reduced incidences of nosocomial infections in surgical patients, etc. (Zhang et al., 2010).

\section{Health benefits of probiotics, probiotics} and synbiotics

The most important and documented beneficial effects of probiotics include the prevention of diarrhea, constipation, changes in bile salt conjugation, enhancement of antibacterial activity, anti-inflammatory. 
Furthermore, they also contribute to the synthesis of nutrients and improve their bioavailability; some probiotics are known to exert anti-oxidative activity in the form of intact cells or lysates. Probiotics have also demonstrated their inherent effects in alleviating symptoms of allergy, cancer, AIDS, respiratory and urinary tract infections. There are stray reports on their beneficial effects on aging, fatigue, autism, osteoporosis, obesity and type 2 diabetes (Harish and Varghese 2006).

\section{Probiotics beneficial effects}

Production of inhibitory substances like $\mathrm{H} 2 \mathrm{O} 2$, bacteriocins, organic acids, etc.,

Blocking of adhesion sites for pathogenic bacteria.

Competition with the pathogenic bacteria for nutrients,

Degradation of toxins as well as the blocking of toxin receptors, Modulation of immune responses.

In conclusions this review probiotics, prebiotics and synbiotics have been discussed with respect to the systemic effects they exert on the host's health, metabolism and immune system. Probiotics, probiotics and synbiotics have systemic effects on the host's health metabolism and immune system. Utilization of prebiotics by probiotics should be a prerequisite for symbiotic selection, in order to maintain a good synergy between the two and maximize the beneficial effects. Probiotics can turn many health benefits to the human, animals, and plants. Applications of probiotics hold many challenges. Probiotics have shown remarkable health benefits to human in a way that their utilization may reduce the use of antibiotics for treatment of diseases such as traveler's diarrhea reducing the risks of antibiotics resistance and other health problems related to microbiota imbalances. Lastly, it is an urging need to establish international standards to regulate probiotics and prebiotics products and functional health claim on the label to ensure product effectiveness and safety.

\section{References}

Agarwal, R. (2005). Probiotics: an Emerging Food Supplement with Health Benefits. Food Biotechnology. 19: 227-246.

Azcarate-Peril, MA; Bruno-Bárcena, JM; Hassan, HM; Klaenhammer, TR. (2006) Transcriptional and Functional Analysis of Oxalyl-Coenzyme A (CoA) Decarboxylase and FormylCoA Transferase Genes from Lactobacillus acidophilus. Appl. Environ. Microbiol., 72(3), 1891-1899.

Brown, AC; Valiere, A. (2004) Probiotics and Medical Nutrition Therapy. Nutr Clin. Care., 7(2), 56-68.

Cencic A, Chingwaru W (2010) The role of functional foods, nutraceuticals, and food supplements in intestinal health. Nutrients 2(6):611-625. doi:10.3390/nu2060611, www.mdpi.com/journal/Nutrients

Cremonini, F; Di Caro, S; Nista, EC; Bartolozzi, F; Capelli, G; Gasbarrini, G; Gasbarrini, A. (2002) Metaanalysis: the Effect of Probiotic Administration on Antibiotic-associated Diarrhoea. Alimentary Pharmacology and Therapeutics, 16, 1461-1467.

Cummings JH, Macfarlane GT (1991) The control and consequences of bacterial fermentation in the human colon. $J$ Appl Bacteriol 70: 443-459.

de Santis, A; Famularo, G; De Simone, C. (2000) Probiotics for the Hemodynamic Alterations of Patients with Liver Cirrhosis. The American Journal of Gastroenterology, 95 (1), 323-324.

de Vrese, M; Stegelmann, A; Richter, B; 
Fenselau, S; Laue, C; Schrezenmeir, J. (2001) Probiotics- Compensation for Lactase Insufficiency. Am. J. Clin. Nutr., 73(2 Suppl), 421S-429S.

Dempsters. (2007). Introducing fibre with a difference, a prebiotic difference.

DeVrese M, Schrezenmeir J (2008) Probiotics, prebiotics, and synbiotics in food biotechnology (pp. 1-66). Springer Berlin Heidelberg

Donaldson, MS. (2004) Nutrition and Cancer: A Review of the Evidence for an Anticancer Diet. Nutr. J., 3, 19.

FAO/WHO (2002) Guidelines for the evaluation of probiotics in foods. Food and Agriculture Organization of the United Nations and World Health Organization Expert Consultation Report. Food and Agricultural Organization of the United Nations and World Health Organization Working Group Report (online).

Federici, F; Vitali, B; Gotti, R; Pasca, MR; Gobbi, S; Peck, AB; Brigidi, P. (2004) Characterization and Heterologous Expression of the Oxalyl Coenzyme A Decarboxylase Gene from Bifidobacterium lactis. Appl. Environ. Microbiol., 70(9), 5066-5073.

Forestier C, De Champs C, Vatoux C and Joly B (2001) Probiotic activities of Lactobacillus casei rhamnosus: in-vitro adherence to intestinal cells and antimicrobial properties. Res Microbiol 152: 167-173.

Fuller R (1989) Probiotics in man and animals. J Appl Bacteriol 66: 65-378.

Galdeano, CM; Perdigón, G. (2006) The Probiotic Bacterium Lactobacillus casei Induces Activation of the Gut Mucosal Immune System through Innate Immunity. Clin. Vaccine Immunol., 13(2), 219-226.

Ghosh, S; van Heel, D; Playford, RJ. (2004) Probiotics in Inflammatory Bowel Disease: Is It All Gut Flora
Modulation? Gut, 53(5), 620-622.

Gueimonde M, Kalliomäki M, Isolauri E, Salminen S (2006) Probiotic Intervention in Neonates-Will Permanent Colonization Ensue? J. pediatr. gastroenterol. nutr. 42(5):604606.

Harish K, Varghese T (2006) Probiotics in humans-evidence based review. Calicut Med J 4(4):e3

Ibrahim F, Ruvio S, Granlund L, Salminen S, Viitanen M, Ouwehand AC (2010) Probiotics and Immunosenescence: Cheese as a Carrier. FEMS immunol. med. microbiol. 59(1):53-59.

Isolauri E, Sütas Y, Kankaanpää P, Arvilommi H, Salminen S (2001) Probiotics: Effects on Immunity. Am. j. clin. nutr. 73:444S-450S.

Isolauri, E; Arvola, T; Sutas, Y; Moilanen, E; Salminen, S. (2000) Probiotics in the Management of Atopic Eczema. Clin. Exp. Allergy, 30, 1604-1610

Jauhiainen Tiina and Korpela Riitta. 2007. Milk Peptides and Blood Pressure. The Journal of Nutrition. 137 (3S): 825S829S.

Johnston, BC; Supina, AL; Vohra, S. (2006) Probiotics for Pediatric Antibioticassociated Diarrhea: a Metaanalysis of Randomized Placebo-controlled Trials. CMAJ, 175(4), 377-383.

Kajander, K; Hatakka, K; Poussa, T; Farkkila, M; Korpela, R. (2005) A Probiotic Mixture Alleviates Symptoms in Irritable Bowel Syndrome Patients: a Controlled 6-month Intervention. Aliment. Pharmacol. Ther., 22(5), 387 394.

Kumar M, Behare PV, Mohania D, Arora S, Kaur A and Nagpal R (2009a) Healthpromoting probiotic functional foods: potential and prospects. Agro Food Ind Hi Tech 20: 29-33.

Kumar M, Kumar A, Nagpal R et al. (2010) Cancer-preventing attributes of 
probiotics: an update. Int J Food Sci Nutr 61: 473-496.

Kumar M, Mohania D, Poddar D, Behare PV, Nagpal R, Kumar A and Aggarwal PK (2009b) A probiotic fermented milk prepared by mixed culture combination reduces pathogen shedding and alleviates disease signs in rats challenged with pathogens. Int $\mathbf{J}$ Probiotics Prebiotics 4: 211-218.

Kumar M, Verma V, Nagpal R, Kumar A, Behare PV, Singh B and Aggarwal PK (2011a) Anticarcinogenic effect of probiotic fermented milk and Chlorophyllin on aflatoxin-B1 induced liver carcinogenesis in rats. Br J Nutr 107: 1006-1016.

Kumar M, Verma V, Nagpal R, Kumar A, Gautam SK, Behare PV, Grover CR and Aggarwal PK (2011b) Effect of probiotic fermented milk and chlorophyllin on gene expressions and genotoxicity during AFB1-induced hepatocellular carcinoma. Gene 490: 54-59.

Lesbros-Pantoflickova, Drahoslava, Corthesy-Theulaz Irene and Blum A.L. 2007. Helicobacter pylori and Probiotics. The Journal of Nutrition. 137(3S): 812S-818S.

Liong, MT; Shah, NP. (2005) Optimization of Cholesterol Removal by Probiotics in the Presence of Prebiotics by Using a Response Surface Method. Appl Environ Microbiol, 71(4), 1745-1753.

Macfarlane GT, Gibson GR (1994) Metabolic activities of the normal colonic flora In S A W Gibson Human health: The contribution of microorganisms, Springer, London.

Macfarlane GT, Macfarlane S (1997) Human colonic microbiota: Ecology physiology and metabolic potential of intestinal bacteria. Scand $\mathbf{J}$ Gastroenterol Suppl 32: 3-9.

MacFarlane, GT; Cummings, JH. (1999)
Probiotics and Prebiotics: Can Regulating the Activities of Intestinal Bacteria Benefit Health? B.M.J., 318, 999-1003

Marteau P, Seksik P, Jian R (2002) Probiotics and Intestinal Health Effects: a Clinical Perspective. Brit. j. nutr. 88:51-58.

Morelli, L; Zonenschain, D; Callegari, ML; Grossi, E; Maisano, F; Fusillo, M. (2003) Assessment of a New Synbiotic Preparation in Healthy Volunteers: Survival, Persistence of Probiotic Strains and Its Effect on the Indigenous Flora. Nutrition Journal, 2(11), 6pp.

Mussatto ST, Mancilha IM (2007) Nondigestible oligosaccharides: A review. Carbohydrate Polymers 68: 587-597.

Nagpal R, Behare PV, Kumar M et al. (2011) Milk, milk products and disease free health: an updated overview. Crit Rev Food Sci Nutr 99999: 1549-7852. (doi: 10.1080/10408398.2010.500231) [Epub ahead of print].

Nagpal R, Kumar A and Arora S (2010) Invitro probiotic potential of lactobacilli from indigenous milk products. Int $\mathrm{J}$ Probiotics Prebiotics 5: 103-110.

Nagpal R, Yadav H, Puniya AK, Singh K, Jain S and Marotta F (2007) Potential of probiotics and prebiotics for symbiotic functional dairy foods. Int $\mathbf{J}$ Probiotics Prebiotics 2: 75-84.

Nam, H; Ha, M; Bae, O; Lee, Y. (2002) Effect of Weissella Confusa Strain PL9001 on the Adherence and Growth of Helicobacter pylori. Appl Environ Microbiol., 68(9), 4642-4645.

O'Sullivan MG (1996) Metabolism of bifidogenic factors by gut flora - An overview. Bulletin of International Dairy Foundation 313: 23-25.

Ouwehand A.C. 2007. Antiallergic Effects of Probiotics. The Journal of Nutrition. 137(3S): 794S-797S. 
Parvez, S; Malik, KA; Kang, SA; Kim, H-Y. (2006) Probiotics and Their Fermented Food Products are Beneficial for Health. Journal of Applied Microbiology, 100, 1171-1185.

Pelletier, X; Laure-Boussuge, S; Donazzolo, Y (2001) Hydrogen Excretion upon Ingestion of Dairy Products in Lactose-intolerant Male Subjects: Importance of the Live Flora. European Journal of Clinical Nutrition, 55(6), 509-512.

Peña AS (2007) Intestinal flora, probiotics, prebiotics, synbiotics and novel foods. Rev Esp Enferm Dig 99(11):653

Penner, RM; Fedorak, RN. (2005) Probiotics in the Management of Inflammatory Bowel Disease. Medscape General Medicine. 7(3), 19.

Pereira, DI; McCartney, AL; Gibson, GR. (2003) An In Vitro Study of the Probiotic Potential of a Bile-SaltHydrolyzing Lactobacillus fermentum Strain, and Determination of Its Cholesterol-Lowering Properties. Appl. Environ. Microbiol., 69(8), 4743-4752.

Pohjavuori, E; Viljanen, M; Korpela, R; Kuitunen, M; Tiittanen, M; Vaarala, O; Savilahti, E. (2004) Lactobacillus GG Effect in Increasing IFN-gamma Production in Infants with Cow's Milk Allergy. J. Allergy Clin. Immunol., 114, 131-136.

Quigley, EMM; Flourie, B. (2007) Probiotics and Irritable Bowel Syndrome: a Rationale for Their Use and an Assessment of the Evidence to Date. Neurogastroenterology and Motility, 19 (3), 166-172.

Reid G, Howard J, Gan B (2001) Can Bacterial Interference Prevent Infection? Trends microbiol. 9:424428.

Reid, G; Burton, J; Devillard, E. (2004) The Rationale for Probiotics in Female
Urogenital Healthcare. Med. Gen. Med., 6(1), 49.

Romeo J, Nova E, Wärnberg J, GómezMartínez S, DíazLigia LE, Marcos A (2010) Immunomodulatory effect of fibres, probiotics and synbiotics in different life-stages. Nutr Hosp 25(3):341-9

Salminen S and Marteau P (1997) Safety of probiotic lactic acid bacteria and other probiotics. Lactic 97 (Proceedings). Adria Normandie Caen, pp. 71-72.

Schrezenmeir, J; de Vrese, M. (2001). Probiotics, Prebiotics and Synbiotics Approching a Definition. Am J. Clin. Nutr, 73 (suppl), 361S-364S.

Sgouras, D; Maragkoudakis, P; Petraki, K; Martinez-Gonzalez, B; Eriotou, E; Michopoulos, S; Kalantzopoulos, G; Tsakalidou, E; Mentis, A. (2004) In Vitro and in Vivo Inhibition of Helicobacter pylori by Lactobacillus casei Strain Shirota. Appl. Environ. Microbiol., 70, 518-526.

Shah N (2000) Probiotic Bacteria: Selective Enumeration and Survival in Dairy Foods. J. dairy sci. 83:894-907.

Solga, SF. (2003) Probiotics Can Treat Hepatic Encephalopathy. Med. Hypotheses, 61, 307-313.

Stanton Catherine, Gardiner Gillian, Meehan Hillary, Collins Kevin, Fitzgerald Gerald, Lynch P Brendan, and Ross R Paul. 2001. Market potential for probiotics. Americal Journal of Clinical Nutrition. 73(suppl):476S$83 \mathrm{~S}$.

Sydorchuk, L; Sydorchuk, G.; Sydorchuk, I. (2005) Vascular Pathology and Immune Disorders in Hypertensive Patients. American Journal of Hypertension, 18(5), A49-A49.

Turnbaugh PJ, Ley RE, Mahowald MA, Magrini V, Mardis ER and Gordon JI (2006) An obesity-associated gut microbiome with increased capacity 
for energy harvest. Nature 444: 10271031.

Twetman S, Stecksen-Blicks C (2008) Probiotics and Oral Health Effects in Children. Int. J. Paediatr. Dent. 18:310.

van Niel, CW; Feudtner, C; Garrison, MM; Christakis, DA. (2002) Lactobacillus Therapy for Acute Infectious Diarrhea in Children: A Meta-analysis. Pedriatrics, 109(4), 678-684.

Vasiljevic T, Shah N (2008) Probiotics-from Metchnikoff to Bioactives. Int. dairy j. 18:714-728.

Weizman, Z; Asli, G; Alsheikh, A. (2005) Effect of a Probiotic Infant Formula on Infections in Child Care Centers: Comparison of Two Probiotic Agents. Pediatrics, 115, 5-9.

Yadav H, Jain S and Sinha PR (2007a) Formation of oligosaccharides in skim milk fermented with mixed dahi cultures, Lactococcus lactis ssp. diacetylactis and probiotic strains of Lactobacilli. J Dairy Res 74: 154-159.

Yadav H, Jain S and Sinha PR (2007b) Antidiabetic effect of probiotic dahi containing Lactobacillus acidophilus, Lactobacillus casei and Lactococcus lactis bacteria in high fructose diet fed rats. Nutrition 72: 62-68.

Yadav H, Jain S and Sinha PR (2008) Oral administration of dahi containing probiotic Lactobacillus acidophilus and Lactobacillus casei ameliorated the Streptozotocin-induced oxidative stress and dyslipidemia in rats. J Dairy Res 75: 189-195.

Zhang MM, Cheng JQ, Lu YR, Yi ZH, Yang $\mathrm{P}, \mathrm{Wu}$ XT (2010) Use of pre-, pro-and synbiotics in patients with acute pancreatitis: a meta-analysis. World J Gastroenterol: WJG 16(31):3970. doi:10.3748/wjg.v16.i31.3970.

\section{How to cite this article:}

Thilagavathi, T. 2020. Probiotics, Prebiotics, Synbiotics and its Health Benefits. Int.J.Curr.Microbiol.App.Sci. 9(11): 497-511. doi: https://doi.org/10.20546/ijcmas.2020.911.061 